\title{
Polyaniline coated conducting fabrics. Chemical and electrochemical characterization
}

\author{
J. Molina ${ }^{\mathrm{a}}$, M.F. Esteves ${ }^{\mathrm{b}}$, J. Fernández $^{\mathrm{a}}$, J. Bonastre ${ }^{\mathrm{a}}$, F. Cases ${ }^{\mathrm{a}, *}$ \\ a Departamento de Ingeniería Textil y Papelera, EPS de Alcoy, Universitat Politècnica de València, Plaza Ferrándiz y Carbonell s/n, 03801 Alcoy, Spain \\ ${ }^{\mathrm{b}}$ Department of Textile Engineering, University of Minho, Campus de Azurém, 4800-058 Guimaraes, Portugal
}

\section{A R T I C L E I N F O}

\section{Article history:}

Received 30 May 2011

Received in revised form 13 July 2011

Accepted 25 July 2011

Available online 4 August 2011

\section{Keywords:}

Polyester

Conducting fabric

Polyaniline

Electrochromism

SECM

Electrochemical characterization

\begin{abstract}
A B S T R A C T
Polyaniline coated conducting fabrics have been obtained by chemical oxidation of aniline by potassium peroxydisulfate on polyester fabrics. Two different acids have been employed to carry out the synthesis $\left(\mathrm{HCl}\right.$ and $\left.\mathrm{H}_{2} \mathrm{SO}_{4}\right)$, obtaining the best results of conductivity with the latter one. The conducting fabrics have been characterized chemically by means of Fourier transform infrared spectroscopy with attenuated total reflection (FTIR-ATR), energy dispersive X-Ray (EDX) and X-ray photoelectron spectroscopy (XPS). The morphology of the coatings has been observed by means of scanning electron microscopy (SEM). The conducting properties of the fabrics have been measured by means of electrochemical impedance spectroscopy (EIS). The electrochemical characterization has been carried out by means of cyclic voltammetry (CV) and scanning electrochemical microscopy (SECM). The conducting fabrics have also shown electrochromic properties, changing its color from green yellowish at $-1 \mathrm{~V}$ to dark green at $+2 \mathrm{~V}$. The durability of the coating has been evaluated by means of washing and rubbing fastness tests.
\end{abstract}

() 2011 Elsevier Ltd. All rights reserved.

\section{Introduction}

The development of fabrics with new properties and applications has received great attention during the last years; one of these properties is the electrical conductivity. Different methods have been employed to produce conducting fabrics, such as the synthesis of conducting polymers on the fabrics. Since the pioneering work of Gregory et al. [1] different works have been published concerning the production of polypyrrole (PPy) or polyaniline (Pani) coated fabrics to produce conductive fabrics [2-17]. The applications of polyaniline coated fabrics are for example as: ammonia sensor [2], electromagnetic shielding [35], static charge dissipation [4], electromechanical devices [6] or precious metals recovery [7].

Conducting polymers can be deposited on fabric surfaces chemically [1-7] or electrochemically $[8,9]$. The chemical deposition is the most widely employed method

\footnotetext{
* Corresponding author. Tel.: +34 966528812; fax: +34 966528438.

E-mail address: fjcases@txp.upv.es (F. Cases).
}

since samples of higher size can be processed. During the formation of conducting polymers such as polypyrrole (PPy) or polyaniline (Pani), positive charges which are responsible for its electronic conduction (polarons and bipolarons) are created in its structure. These charges are compensated by counter ions to maintain the electroneutrality principle. In polyaniline synthesis, the counter ions employed are usually the same acids employed to produce the acidic medium. This acid medium is needed for obtaining polyaniline in its conducting form. Different textile substrates have been coated with polyaniline, like: polyester $[1,3,6,10-17]$, nylon $6[1,2,7,10,14]$, wool [10,14], acrylics $[10,14]$, cotton $[5,10,14]$, silica [3,4], glass [3] or quartz [1]. In the present study, we have employed polyester (PES) since this synthetic polymer is not damaged by the acid media employed to carry out the synthesis.

The chemical characterization of the conducting fabrics obtained has been performed by Fourier transform infrared spectroscopy with attenuated total reflection (FTIR-ATR), energy dispersive X-ray (EDX) and X-ray photoelectron spectroscopy measurements (XPS). XPS measurements 
allow the analysis of the surface composition, as well as counter ion content and the quantification of the doping level $\left(\mathrm{N}^{+} / \mathrm{N}_{\text {Total }}\right)$. Doping level is an important parameter in conducting polymers; this parameter indicates the oxidation state of the polymer. The electrical characterization of conducting fabrics has been performed by electrochemical impedance spectroscopy measurements (EIS). The electroactivity of the samples has been measured employing scanning electrochemical microscopy (SECM) and cyclic voltammetry (CV). Very little has been reported about the electrochemical characterization of conducting fabrics and there is a lack in these field. In bibliography only a few assays of CV have been performed on polyaniline coated conducting fabrics [18]. In the present paper we report the influence of the scan rate in the characterization of polyaniline conducting fabrics. SECM is a relatively novel(1989) and powerful technique that is becoming more popular among researchers [19-28]. SECM has been employed in conducting polymers field for different purposes such as to study ion and electron transport [23], detect degradation products of conducting polymers [24] or produce the growth of conducting polymers creating patterns $[25,26]$ or towers [27].

This technique allows zonal analysis of electroactivity without polarizing the sample to study. SECM has not been widely used for the analysis of conducting fabrics, and only our previous study is reported in bibliography [28]. In that publication we studied polypyrrole coated conducting fabrics and we demonstrated that SECM is a useful technique for the electrochemical analysis of these materials.

\section{Experimental}

\subsection{Reagents and materials}

All reagents employed were of analytical grade.

For the synthesis: aniline $\left(\mathrm{C}_{6} \mathrm{H}_{5} \mathrm{NH}_{2}\right)$, sulfuric acid $\left(\mathrm{H}_{2} \mathrm{SO}_{4}\right)$, hydrochloric acid $(\mathrm{HCl})$ and potassium peroxydisulfate $\left(\mathrm{K}_{2} \mathrm{~S}_{2} \mathrm{O}_{8}\right)$ were purchased from Merck. Normapur acetone $\left(\left(\mathrm{CH}_{3}\right)_{2} \mathrm{CO}\right)$ was from Prolabo. Polyester fabrics were acquired from Viatex S.A. and their characteristics were: fabric surface density, $140 \mathrm{~g} \mathrm{~m}^{-2}$; warp threads per $\mathrm{cm}, 20$ (warp linear density, $167 \mathrm{dtex}$ ); weft threads per $\mathrm{cm}, 60$ (weft linear density, 500 dtex). These are specific terms used in the field of textile industry and their meaning can be consulted in a textile glossary [29].

For the characterization: Sulfuric acid $\left(\mathrm{H}_{2} \mathrm{SO}_{4}\right)$, hydrochloric acid $(\mathrm{HCl})$, sodium sulfate $\left(\mathrm{Na}_{2} \mathrm{SO}_{4}\right)$ and sodium hydroxide $(\mathrm{NaOH})$ were purchased from Merck. Sodium chloride $(\mathrm{NaCl})$ was from Fluka. Hexaammineruthenium(III) choride $\left(\mathrm{Ru}\left(\mathrm{NH}_{3}\right)_{6} \mathrm{Cl}_{3}\right)$ was used as received from Acros Organics. When needed, solutions were deoxygenated by bubbling nitrogen $\left(\mathrm{N}_{2}\right.$ premier X50S). Ultrapure water was obtained from an Elix 3 Millipore-Milli-Q Advantage A10 system with a resistivity near to $18.2 \mathrm{M} \Omega \mathrm{cm}$.

\subsection{Chemical synthesis of polyaniline on polyester fabrics}

Fabrics of $6 \mathrm{~cm} \times 6 \mathrm{~cm}$ were coated with polyaniline. Polyester was degreased with acetone in ultrasound bath prior to reaction. Aqueous solutions of $2 \mathrm{~g} \mathrm{~L}^{-1}$ of aniline were employed to carry out the synthesis. The oxidant to monomer ratio employed to produce the polymerization was the optimal found in bibliography (1.25) [30]. An acid $\mathrm{pH}$ was employed to carry out the synthesis; $\mathrm{H}_{2} \mathrm{SO}_{4}$ or $\mathrm{HCl}$ were employed to obtain the acid medium and their concentration was $0.2 \mathrm{M}$. To neutralize the positive charges created during the synthesis of polyaniline, the acids also acted as doping counter ions. The following stage was the adsorption of aniline and the doping acid on the fabric during $30 \mathrm{~min}$ at room temperature. After this time, $\mathrm{K}_{2} \mathrm{~S}_{2} \mathrm{O}_{8}$ solution $(50 \mathrm{ml})$ was added drop wise and reaction elapsed during $180 \mathrm{~min}$ without mechanical agitation. Adsorption and reaction took place in a precipitates beaker. It is worth mentioning that aniline polymerization has an induction period [30]. This induction period depends on the concentration of reactants; in the experimental conditions employed in the present work this time was around $10 \mathrm{~min}$. After the reaction time, the coated fabric was washed with an aqueous acid solution $\left(0.2 \mathrm{M} \mathrm{H}_{2} \mathrm{SO}_{4}\right.$ or $\left.0.2 \mathrm{M} \mathrm{HCl}\right)$ to remove polyaniline not joined to the fibers. An acid washing solution is needed to avoid deprotonation of polyaniline [31]. Polyaniline powders were obtained after filtering the synthesis solution. Conducting fabrics and polyaniline powders were dried in a desiccator during at least $24 \mathrm{~h}$ before measurements. Three samples were obtained and their weight increase was averaged. The weight increase for the fabrics coated with Pani/ $/ \mathrm{HSO}_{4}^{-}$and Pani $/ \mathrm{Cl}^{-}$was $6 \%$ and $2 \%$, respectively. Different measurements were performed with each of the techniques employed (EIS, FTIRATR, SEM, etc.) obtaining similar results, although only one measurement for each sample type (PES-Pani/HSO or PES-Pani $/ \mathrm{Cl}^{-}$) has been included in the text.

\subsection{FTIR-ATR measurements}

Fourier transform infrared spectroscopy with horizontal multirebound attenuated total reflection (FTIR-ATR) was performed with a Nicolet 6700 Spectrometer equipped with DTGS detector. An accessory with pressure control was employed to equalize the pressure in the different solid samples. A prism of ZnSe was employed. Spectra were collected with a resolution of $4 \mathrm{~cm}^{-1}$ and 400 scans were averaged for each sample.

\subsection{Scanning electron microscopy and energy dispersive X-ray characterization}

A Jeol JSM-6300 scanning electron microscope was employed to observe the morphology of the samples and perform EDX analyses. Scanning electron microscopy (SEM) analyses were performed using an acceleration voltage of $20 \mathrm{kV}$. EDX measurements were done between 0 and $20 \mathrm{keV}$. Samples for SEM measurements were coated with Au employing a Sputter Coater Bal-Tec SCD 005. When EDX measurements were carried out, samples were coated with $\mathrm{C}$ to avoid the interference of Au in the EDX spectra.

\subsection{X-ray photoelectron spectroscopy}

XPS analyses were conducted at a base pressure of $5 \times 10^{-10}$ mbars and a temperature around $-100^{\circ} \mathrm{C}$. XPS 
spectra were obtained with a VG-Microtech Multilab electron spectrometer by using unmonochromatized $\mathrm{Mg} \mathrm{K \alpha}$ $(1253.6 \mathrm{eV})$ radiation from a twin anode source operating at $300 \mathrm{~W}(20 \mathrm{~mA}, 15 \mathrm{kV})$. The binding energy (BE) scale was calibrated with reference to the $\mathrm{C} 1 \mathrm{~s}$ line at $284.6 \mathrm{eV}$. The N1s and $\mathrm{C} 1 \mathrm{~s}$ high resolution core level spectra for the samples of PES-Pani/ $/ \mathrm{HSO}_{4}^{-}$and PES-Pani $/ \mathrm{Cl}^{-}$were obtained. The doping level of the polymers was calculated from the ratio $\mathrm{N}^{+} / \mathrm{N}_{\text {Total }}$.

\subsection{Electrical and electrochemical measurements}

An Autolab PGSTAT302 potentiostat/galvanostat was employed to perform electrochemical impedance spectroscopy (EIS) analyses. EIS measurements were performed in the $10^{5}-10^{-2} \mathrm{~Hz}$ frequency range. The amplitude of the sinusoidal voltage was $\pm 10 \mathrm{mV}$. Measurements were carried out in a two-electrode arrangement. Two types of configuration were employed to carry out the measurements. In the first one, the sample was located between two round copper electrodes $\left(A=1.5 \mathrm{~cm}^{2}\right)$. In the second configuration, two rectangular copper electrodes $(0.5 \mathrm{~cm} \times 1.5 \mathrm{~cm})$ separated by $1.5 \mathrm{~cm}$ and pressed on the fabric sample were employed. The measured area of the fabric with this configuration was a square of $1.5 \mathrm{~cm}$ so the measured impedance modulus $(\Omega)$ was equal to the surface resistivity $(\Omega / \square)[32]$.

\subsection{Cyclic voltammetry measurements}

An Autolab PGSTAT302 potentiostat/galvanostat was employed to perform $\mathrm{CV}$ measurements in the different pH solutions: $\mathrm{pH} \sim 0 \quad\left(0.5 \mathrm{M} \mathrm{H}_{2} \mathrm{SO}_{4}\right), \mathrm{pH} \sim 0.7 \quad(0.1 \mathrm{M}$ $\left.\mathrm{H}_{2} \mathrm{SO}_{4}\right)$ and $\mathrm{pH} \sim 13\left(0.1 \mathrm{M} \mathrm{NaOH}\right.$ and $\left.0.1 \mathrm{M} \mathrm{Na}_{2} \mathrm{SO}_{4}\right)$. The conducting fabric sample was located between two Ti plates to connect the sample with the potentiostat/galvanostat. The measurements were performed in a three electrode arrangement. The counter electrode employed was made of stainless steel; the pre-treatment consisted on polishing, degreasing with acetone in an ultrasonic bath and washing with water in the ultrasonic bath. The working electrode was made by cutting a strip of the polyaniline coated conducting fabric. Potential measurements were referred to $\mathrm{Ag} / \mathrm{AgCl}(3 \mathrm{M} \mathrm{KCl})$ reference electrode. Oxygen was removed from solution by bubbling nitrogen gas for 10 min and then a $\mathrm{N}_{2}$ atmosphere was maintained during the measurements. The ohmic potential drop was measured and introduced in the Autolab software (GPES). The measurements were done between -0.2 and $+0.7 \mathrm{~V}$. The characterization by means of $\mathrm{CV}$ has been done at different scan rates as it has been corroborated the influence of this parameter on the electrochemical response obtained. The scan rates employed were 50,5 and $1 \mathrm{mV} \mathrm{s}^{-1}$.

\subsection{Scanning electrochemical microscopy}

SECM measurements were carried out with a scanning electrochemical microscope of Sensolytics. The three electrode cell configuration consisted of a $100 \mu \mathrm{m}$ diameter Pt ultra-microelectrode (UME) working electrode, a Pt wire auxiliary electrode and an $\mathrm{Ag} / \mathrm{AgCl}(3 \mathrm{M} \mathrm{KCl})$ reference electrode. The solutions selected for the measurements were aqueous solutions of $0.01 \mathrm{M} \mathrm{Ru}\left(\mathrm{NH}_{3}\right)_{6} \mathrm{Cl}_{3}$ (redox mediator) with $0.1 \mathrm{M} \mathrm{Na}_{2} \mathrm{SO}_{4}$ or $\mathrm{NaCl}$, for PES-Pani/HSO $\mathrm{H}_{4}^{-}$ and PES-Pani $/ \mathrm{Cl}^{-}$, respectively. Two different $\mathrm{pHs}$ were employed to perform the measurements (2.4 and 5.4). $\mathrm{H}_{2} \mathrm{SO}_{4} / \mathrm{NaOH}$ and $\mathrm{HCl} / \mathrm{NaOH}$ were employed to adjust the $\mathrm{pH}$ solutions for the samples of PES-Pani/ $\mathrm{HSO}_{4}^{-}$and PESPani $/ \mathrm{Cl}^{-}$, respectively. All the experiments were carried out in inert nitrogen atmosphere. PES, PES-Pani/HSO ${ }_{4}^{-}$ and PES-Pani $/ \mathrm{Cl}^{-}$fabrics were chosen as substrate materials. The substrates were glued with epoxy resin on glass microscope slides.

The Pt UME tip was moved in $z$ direction and the tip current was recorded to obtain the approach curves. Approach curves give us an indication of the electroactivity of the surface. These curves were compared to the theoretical ones (positive and negative feedback models). Then, the electrode was positioned at the desired height to carry out the constant-height SECM images in the plane $x y$. The substrate surfaces in all the measurements were at their open circuit potential (OCP).

\subsection{Washing and rubbing fastness tests}

Washing and rubbing fastness tests were performed to test the resistance of the polyaniline coatings to physical actions. Washing tests were performed according to the norm ISO 105-C06-2010. The test applied was the A1s $\left(40^{\circ} \mathrm{C}, 30 \mathrm{~min}\right)$. Rubbing fastness tests of fabrics coated with polyaniline were performed as explained in the norm ISO 105-X12:2001. Each sample was abraded against cotton abrasive fabric for 10 cycles. These analyses were performed only for PES-Pani/HSO ${ }_{4}^{-}$fabrics, where the best results of conductivity were obtained.

\section{Results and discussion}

\subsection{FTIR-ATR measurements}

Fig. 1 shows the FTIR-ATR spectra of Pani/Cl' ${ }^{-}$and Pani/ $\mathrm{HSO}_{4}^{-}$powders obtained by filtering the synthesis solution after coating polyester fabrics with polyaniline. The spectra of Pani powders were done to assign the different contributions of polyaniline that may appear in the spectra of Pani coated fabrics. As can be appreciated in Fig. 1, both spectra are identical and present the same bands. The different polyaniline bands observed were:

- Band centered at $1550 \mathrm{~cm}^{-1}$, stretching of quinoid ring $\mathrm{N}=\mathrm{Q}=\mathrm{N}[33]$.

- Band centered at $1465 \mathrm{~cm}^{-1}$, stretching of benzene ring [33].

- Band centered at $1290 \mathrm{~cm}^{-1}$, stretching of $\mathrm{C}-\mathrm{N}$ in secondary amines [33].

- Bands centered at 1232, 1120 and $1025 \mathrm{~cm}^{-1}, \mathrm{C}-\mathrm{H}$ in plane bending of 1,4-ring [33].

- Band centered at $864 \mathrm{~cm}^{-1}, \mathrm{C}-\mathrm{H}$ out-of-plane bending of 1,2,4-ring [33].

- Band centered at $789 \mathrm{~cm}^{-1}, \mathrm{~N}-\mathrm{H}$ out-of-plane bending [34]. 


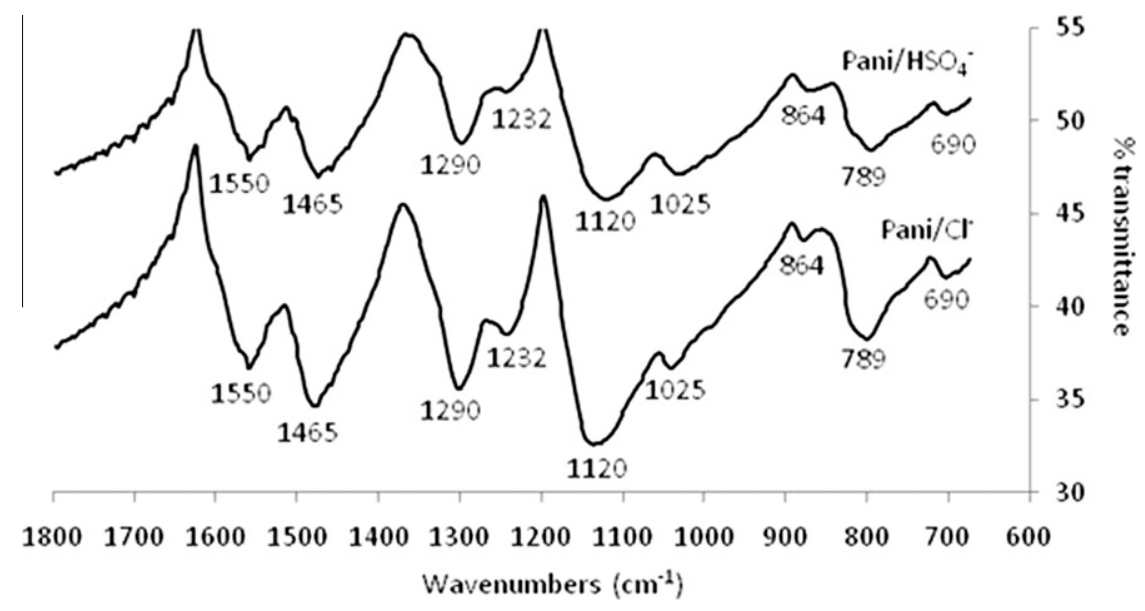

Fig. 1. FTIR-ATR spectra of Pani/ $\mathrm{HSO}_{4}^{-}$and Pani $/ \mathrm{Cl}^{-}$powders. Resolution $4 \mathrm{~cm}^{-1}, 400$ scans.

- Band centered at $690 \mathrm{~cm}^{-1}, \mathrm{C}-\mathrm{H}$ out-of-plane bending of 1,2-ring [33].

Fig. 2 shows the FTIR spectra of PES, PES-Pani/ $/ \mathrm{Cl}^{-}$and PES-Pani/HSO ${ }_{4}^{-}$. In the spectrum of polyester, its different bands can be observed. The most representative bands are: $720 \mathrm{~cm}^{-1}$ (out of plane vibration of benzene group) [35]; $960 \mathrm{~cm}^{-1}$ (C-O stretching of glycol) [35]; $1014 \mathrm{~cm}^{-1}$ (in-plane vibration of benzene) [35]; $1090 \mathrm{~cm}^{-1}$ (ester $\mathrm{C}=\mathrm{O}$ stretching) [35]; $1236 \mathrm{~cm}^{-1}$ (ester $\mathrm{C}=\mathrm{O}$ stretching) [35] and $1714 \mathrm{~cm}^{-1}(\mathrm{C}=\mathrm{O}$ stretching of aromatic ester) [36]. If we compare the spectra of PES and PES coated with polyaniline, only significant differences can be found for the sample of PES-Pani/HSO ${ }_{4}^{-}$. In the case of PES-Pani $/ \mathrm{Cl}^{-}$ the thickness of the coating seems to be lesser than in the case of PES-Pani/ $/ \mathrm{HSO}_{4}^{-}$, so polyaniline bands cannot be clearly observed. Weight increase measurements of the fabrics also indicated this fact (2\% for PES-Pani $/ \mathrm{Cl}^{-}$ vs. $6 \%$ for PES-Pani/ $/ \mathrm{HSO}_{4}^{-}$). For the sample of PES-Pani/ $\mathrm{HSO}_{4}^{-}$the bands that have been observed and indicate the presence of polyaniline are 1160 and $1031 \mathrm{~cm}^{-1}(\mathrm{C}-\mathrm{H}$ in plane bending of 1,4-ring) [33] and $1550 \mathrm{~cm}^{-1}$ (stretching of quinoid ring $\mathrm{N}=\mathrm{Q}=\mathrm{N}$ ) [33].

\subsection{Scanning electron microscopy and energy dispersive X-ray characterization}

Fig. 3 shows the micrographs of the conducting fabrics of PES-Pani/HSO $\mathrm{HS}_{4}^{-}$(Fig. 3a-d) and PES-Pani/ $/ \mathrm{Cl}^{-}$(Fig. 3e and f). The micrographs were obtained by secondary electrons.

The original fibers of polyester present a very smooth surface (figure not shown). Fig. 3a shows the PES-Pani/ $\mathrm{HSO}_{4}^{-}$fabric at low magnification. With this magnification the polyaniline coating cannot be observed. In the formation of polypyrrole on polyester fabrics, the formation of aggregates not joined to the fibers was noticeable [32]. However, in both polyaniline coated conducting fabrics (PES-Pani/HSO $\mathrm{HS}_{4}^{-}$and PES-Pani $/ \mathrm{Cl}^{-}$), no aggregates could be found on the surface of the fibers. Fig. 3b-d show some fibers of the PES-Pani/HSO- fabric with higher magnification. In these micrographs the layer of polyaniline can be

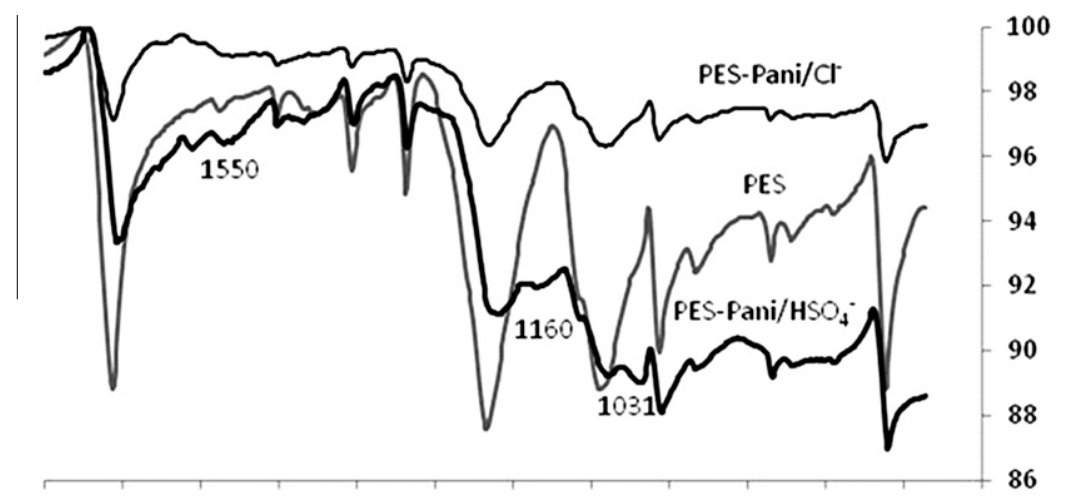

$\begin{array}{lllllllllllll}1800 & 1700 & 1600 & 1500 & 1400 & 1300 & 1200 & 1100 & 1000 & 900 & 800 & 700 & 600\end{array}$

Wavenumbers $\left(\mathrm{cm}^{-1}\right)$

Fig. 2. FTIR-ATR spectra of PES, PES-Pani/HSO $\mathrm{HS}_{4}^{-}$and PES-Pani/Cl- . Resolution $4 \mathrm{~cm}^{-1}, 400$ scans. 

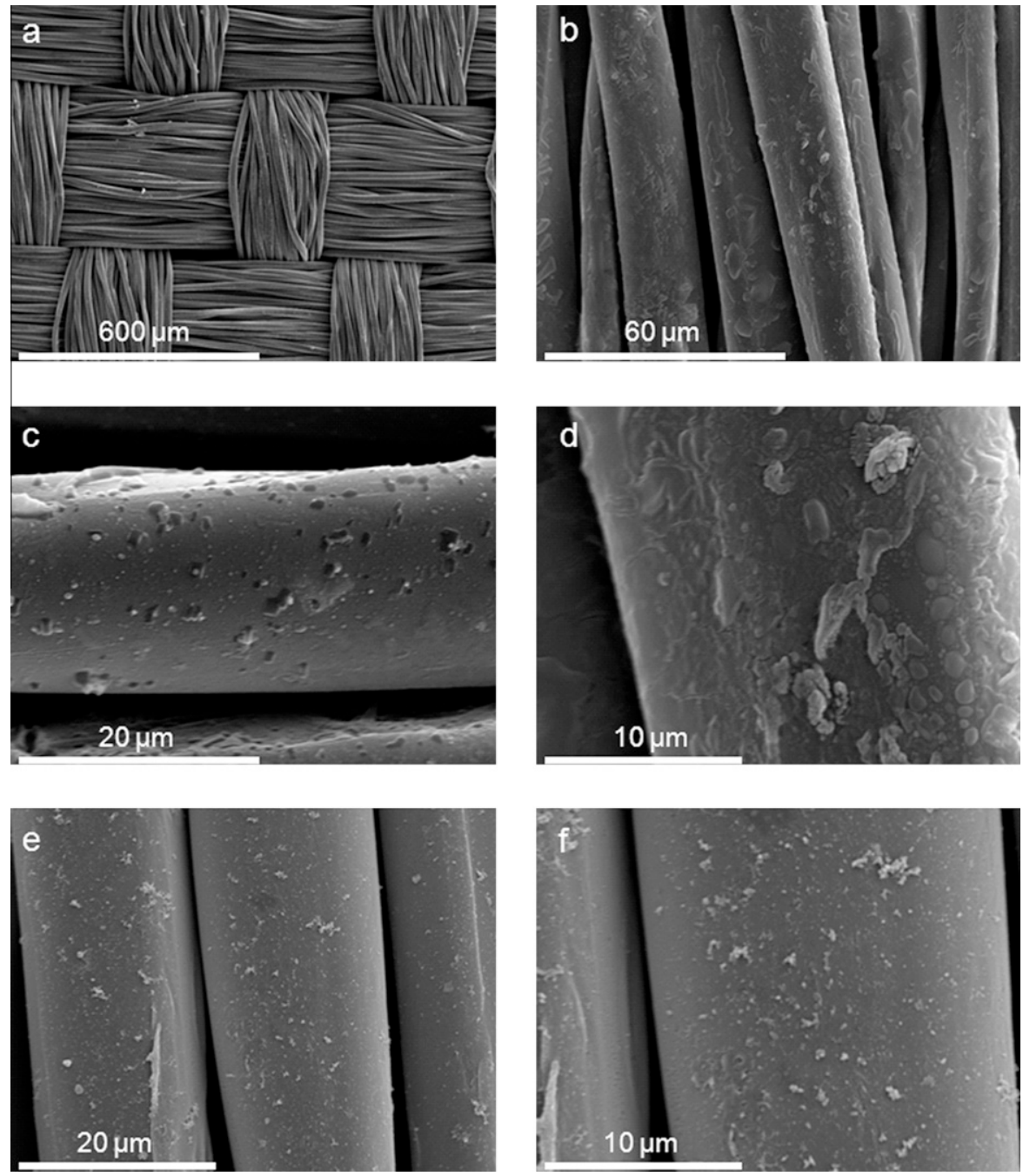

Fig. 3. Micrographs of: PES-Pani/HSO $-\mathrm{H}_{4}^{-}$(a) $100 \times$; (b) $1000 \times$; (c) $3000 \times$; (d) $5000 \times$ and $\mathrm{PES}-\mathrm{Pani} / \mathrm{Cl}^{-}$(e) $2500 \times$; (f) $5000 \times$.

clearly observed. The coating presents a flaky and globular morphology. Fig. 3e and f show micrographs of PES-Pani/ $\mathrm{Cl}^{-}$fabric. It can be seen that the morphology of the coating is completely different from the previous one. In this case the coating is quite smooth and with lower grain size.

EDX analyses were done to prove the incorporation of the doping acids as counter ions in the Pani structure. Fig. 4a, shows the EDX spectrum for the PES-Pani/HSO ${ }_{4}^{-}$ sample. As can be seen, the presence of a band attributed to sulfur ( $\mathrm{SK} \alpha 2.307 \mathrm{keV})$ [37] in the EDX spectrum indicates the incorporation of $\mathrm{HSO}_{4}^{-}$as counter ion in the structure of polyaniline. In the case of PES-Pani $/ \mathrm{Cl}^{-}$, the presence of the band $\mathrm{ClK} \alpha 2.622 \mathrm{keV}$ [37] indicates the incorporation of $\mathrm{Cl}^{-}$as doping counter ions (Fig. 4b). These results were also confirmed by XPS measurements.

\subsection{X-ray photoelectron spectroscopy}

XPS measurements were performed to quantify the amount of counter ion $\left(\mathrm{HSO}_{4}^{-}\right.$and $\left.\mathrm{Cl}^{-}\right)$and doping ratio
$\left(\mathrm{N}^{+} / \mathrm{N}_{\text {Total }}\right)$ of the conducting fabrics of PES-Pani/HSO and PES-Pani $/ \mathrm{Cl}^{-}$. The $\mathrm{C} 1 \mathrm{~s}$ and $\mathrm{N} 1 \mathrm{~s}$ core levels spectra were analyzed for both samples.

Fig. 5 shows the high resolution N1s spectra for the samples of PES-Pani/ $/ \mathrm{HSO}_{4}^{-}$(a) and PES-Pani $/ \mathrm{Cl}^{-}$(b). The $\mathrm{N} 1 \mathrm{~s}$ spectrum of PES-Pani/HSO ${ }_{4}^{-}$was deconvoluted in three peaks centered at 399.4, 401.54 and $403.3 \mathrm{eV}$. The first peak at $399.4 \mathrm{eV}$ was attributed to the neutral amine-like (-NH-) structure [33]. The peak at $401.6 \mathrm{eV}$ was attributed to nitrogen atoms with a positive charge, polaronic nitrogen $\mathrm{N}^{+}$[33]. The peak at $403.3 \mathrm{eV}$ has been assigned to positively charged nitrogen atoms in a large number of environments arising from inter and intra-chain distribution [33]. The doping ratio can be calculated by the ratio $\mathrm{N}^{+} / \mathrm{N}_{\text {Total }}$ obtaining a value of 0.66 , value higher than the theoretical maximum one (0.50). Such high doping levels have been observed in $\mathrm{Pani} / \mathrm{HSO}_{4}^{-}$powders and have been attributed to the protonation of the imine nitrogens of the emeraldine as well as the protonation of part of the amine nitrogens [38]. These high doping levels are 
(a)

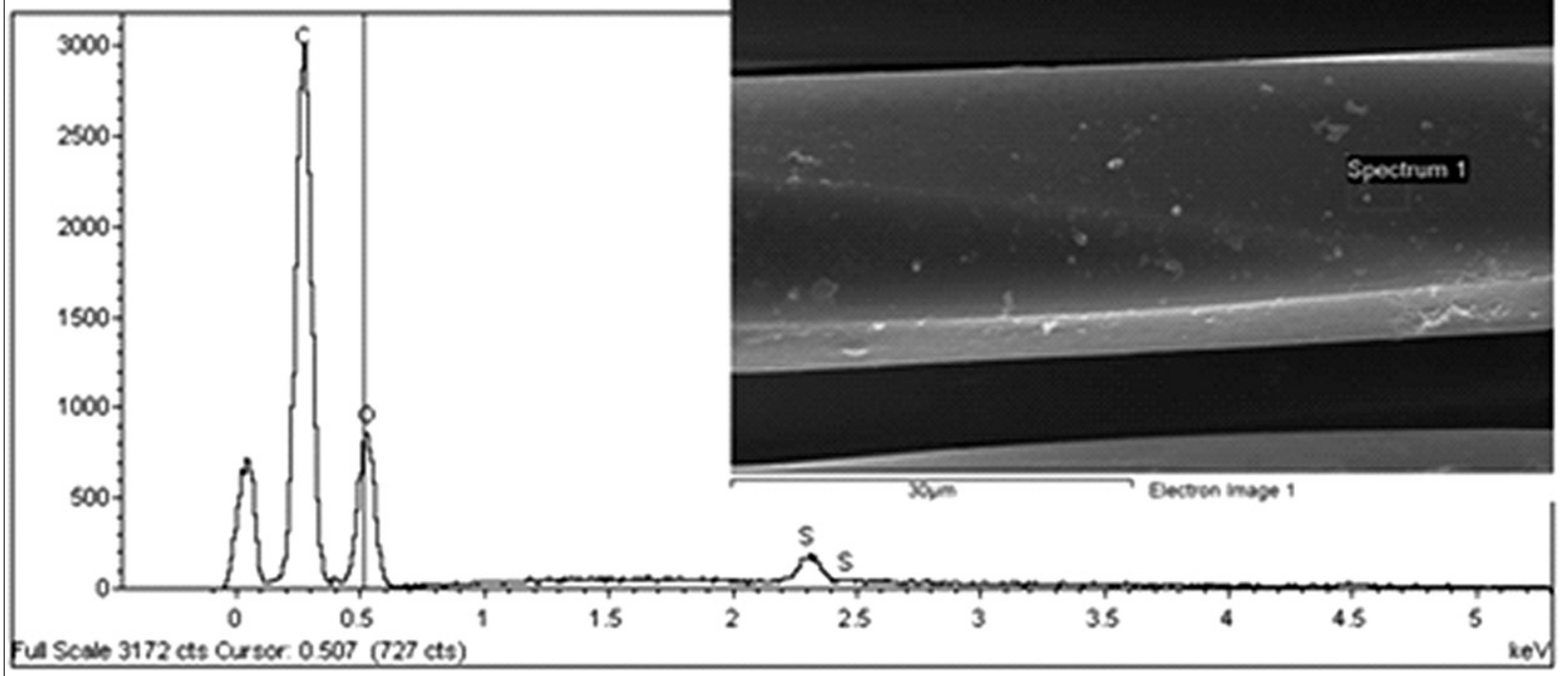

(b)

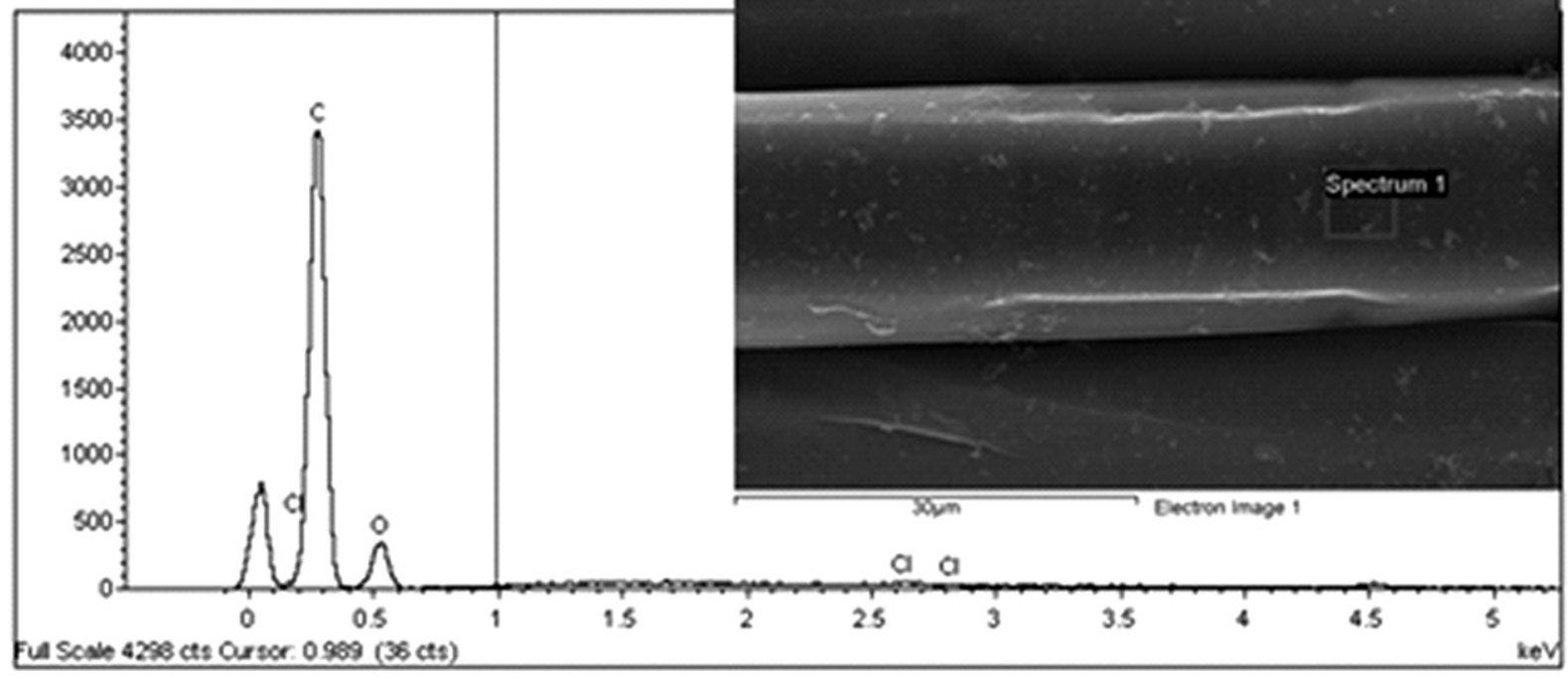

Fig. 4. Micrographs and EDX measurements of PES-Pani/HSO $\mathrm{HS}_{4}^{-}$(a) and PES-Pani/ $/ \mathrm{Cl}^{-}$(b).

produced in the presence of an excess of protonic acid [38]. The N1s spectrum of PES-Pani/Cl ${ }^{-}$showed two contributions: 399.2 and $400.8 \mathrm{eV}$ attributed to neutral amine-like structure $(-\mathrm{NH}-)$ and polaronic nitrogen $\mathrm{N}^{+}$, respectively. The doping ratio $\left(\mathrm{N}^{+} / \mathrm{N}_{\text {Total }}\right)$ for this sample was 0.28 .

Table 1 shows chemical composition and doping ratio $\left(\mathrm{N}^{+} / \mathrm{N}_{\text {Total }}\right)$ for both samples. These coatings should ideally have the formula $\mathrm{C}_{6} \mathrm{H}_{7} \mathrm{~N}\left(\mathrm{HSO}_{4}^{-} / \mathrm{Cl}^{-}\right)_{x}$, where " $x$ " is the fractional counter ion content obtained by $\mathrm{S}$ and $\mathrm{Cl}$ analysis. XPS analyses showed a systematic carbon excess, which may be due to surface hydrocarbon contamination [39]. The composition analysis showed also an oxygen excess, maybe arising from Pani overoxidation during the synthesis. For the sample of PES-Pani $/ \mathrm{Cl}^{-}$, both $\mathrm{Cl}^{-}$and $\mathrm{HSO}_{4}^{-}$ were incorporated as counter ions. $\mathrm{HCl}$ was the doping acid employed, however during Pani formation, peroxydisulphate decomposes into sulfates [30] so $\mathrm{HSO}_{4}^{-}$can also be partially incorporated in the structure of Pani. The sum of the content of $\mathrm{S}$ and $\mathrm{Cl}$ in the chemical composition (Table 1 ) was 0.30 , value very close to the doping level obtained 

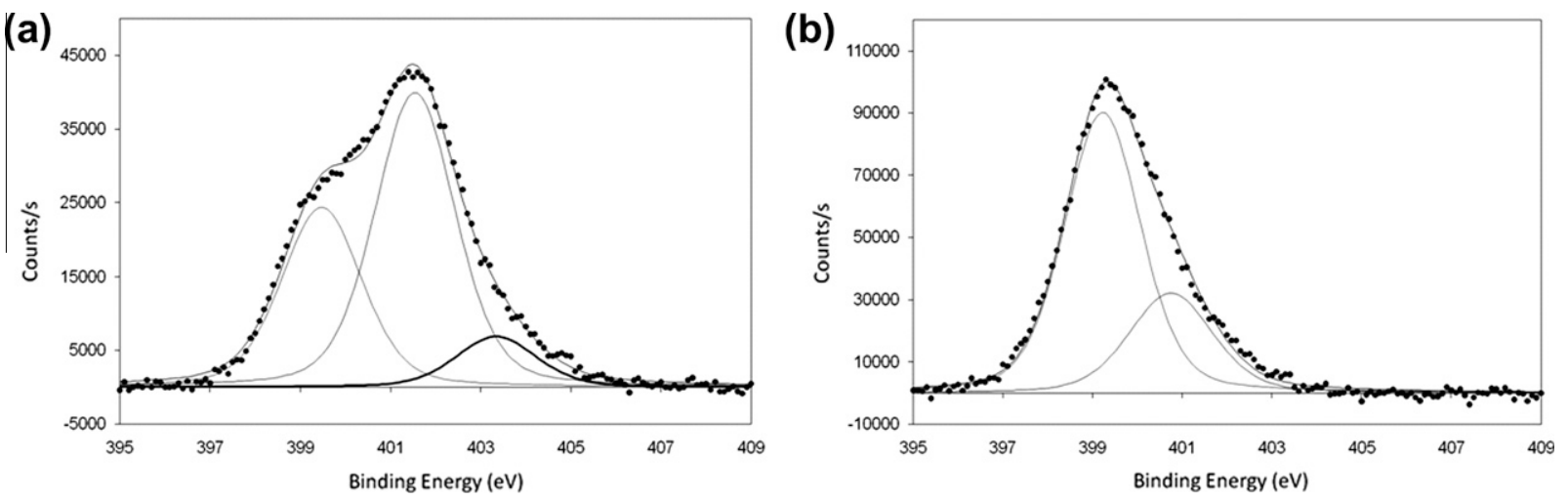

Fig. 5. XPS high resolution spectra for N1s for: (a) PES-Pani/ $/ \mathrm{HSO}_{4}^{-}$and (b) $\mathrm{PES}-\mathrm{Pani} / \mathrm{Cl}^{-}$.

Table 1

Chemical composition and doping ratio $\left(\mathrm{N}^{+} / \mathrm{N}_{\text {Total }}\right)$ for PES-Pani $/ \mathrm{Cl}^{-}$and PES-Pani/HSO ${ }_{4}^{-}$.

\begin{tabular}{lll}
\hline Sample & Chemical composition & $\begin{array}{l}\text { Doping ratio } \\
\left(\mathrm{N}^{+} / \mathrm{N}_{\text {TOTAL }}\right)\end{array}$ \\
\hline PES-Pani/Cl & & 0.28 \\
PES-Pani $/ \mathrm{HSO}_{4}^{-}$ & $\mathrm{C}_{9.15} \mathrm{NCl}_{0.23}\left(\mathrm{HSO}_{4}^{-}\right)_{0.07} \mathrm{O}_{1.23}$ & $\left.0.04 \mathrm{HSO}_{4}^{-}\right)_{1.27} \mathrm{O}_{0.36}$ \\
\hline
\end{tabular}

by $\mathrm{N}^{+} / \mathrm{N}$ ratio (0.28). For the sample of PES-Pani/HSO $\mathrm{H}_{4}^{-}$, $\mathrm{HSO}_{4}^{-}$was incorporated as counter ion. The counter ion content in this case was 1.27 (Table 1 ), value much higher than that of the doping level obtained by $\mathrm{N}^{+} / \mathrm{N}$ ratio $(0.66)$. So there is an excess of $\mathrm{S}$ that has been incorporated into the structure of Pani. This excess has been attributed to the formation of a film of adsorbed molecular $\mathrm{H}_{2} \mathrm{SO}_{4}$ on the surface of the polymer [38]. This excess of incorporated protonic acid caused the increase of the doping level to 0.66 , due to the protonation of part of the amine units.

The $\mathrm{C} 1 \mathrm{~s}$ analyses showed the presence of the different bands for both fabrics (figure not shown). For the sample coated with Pani/HSO ${ }_{4}^{-}$three contributions for the $\mathrm{C} 1 \mathrm{~s}$ spectrum were obtained: 284.2, 285.7 and $287.7 \mathrm{eV}$. The same contributions with similar binding energies were obtained for the PES-Pani $/ \mathrm{Cl}^{-}$sample. The contribution at $284.2 \mathrm{eV}$ was assigned to $\mathrm{C}-\mathrm{C}$ [40]. The second peak at $285.7 \mathrm{eV}$ is due to $\mathrm{C}-\mathrm{N}$ groups of the aniline ring [40]. Finally, the third peak is attributed to $\mathrm{C}=\mathrm{O}$ or $\mathrm{C}-\mathrm{O}-\mathrm{H}$ groups [41] that appear due to the overoxidation caused during the synthesis by the oxidant (peroxydisulphate), that presents a standard redox potential of $2.123 \mathrm{~V}$ [42]. The overoxidation degree can be calculated by the ratio $C_{287.7} \mathrm{ev} /$ $\mathrm{C}_{\text {Total }}$, obtaining a value of $9 \%$ and $10 \%$ for the samples of Pani $/ \mathrm{HSO}_{4}^{-}$and Pani $/ \mathrm{Cl}^{-}$, respectively.

\subsection{Electrical and electrochemical measurements}

Fig. 6 shows the Bode diagrams for the samples of PES, PES-Pani/HSO ${ }_{4}^{-}$and PES/Pani- $\mathrm{Cl}^{-}$. The data shown in these graphics were measured with the configuration where the sample was located between two round copper electrodes. In Fig. 6a, it can be seen the impedance modulus $(|Z|)$ at the different frequencies for the different samples. The sample of polyester presents a value of the impedance modulus at low frequencies higher than $10^{11} \Omega$, typical value of insulating materials. When the sample of polyester was coated with Pani/ $/ \mathrm{HSO}_{4}^{-}$, the value of the impedance modulus lowered more than nine orders of magnitude (a value of approximately $49 \Omega$ was obtained). In the PES-Pani/HSO ${ }_{4}^{-}$ fabric there could be also a contribution to the conduction from the $\mathrm{H}_{2} \mathrm{SO}_{4}$ excess incorporated in the polymer structure (as XPS measurements revealed). However, ionic and electronic contributions could not be discerned since both processes were overlapped in the resistive process observed in EIS measurements. When Pani $/ \mathrm{Cl}^{-}$was deposited, the value of impedance modulus obtained was $496 \Omega$. The values of surface resistivity obtained with the

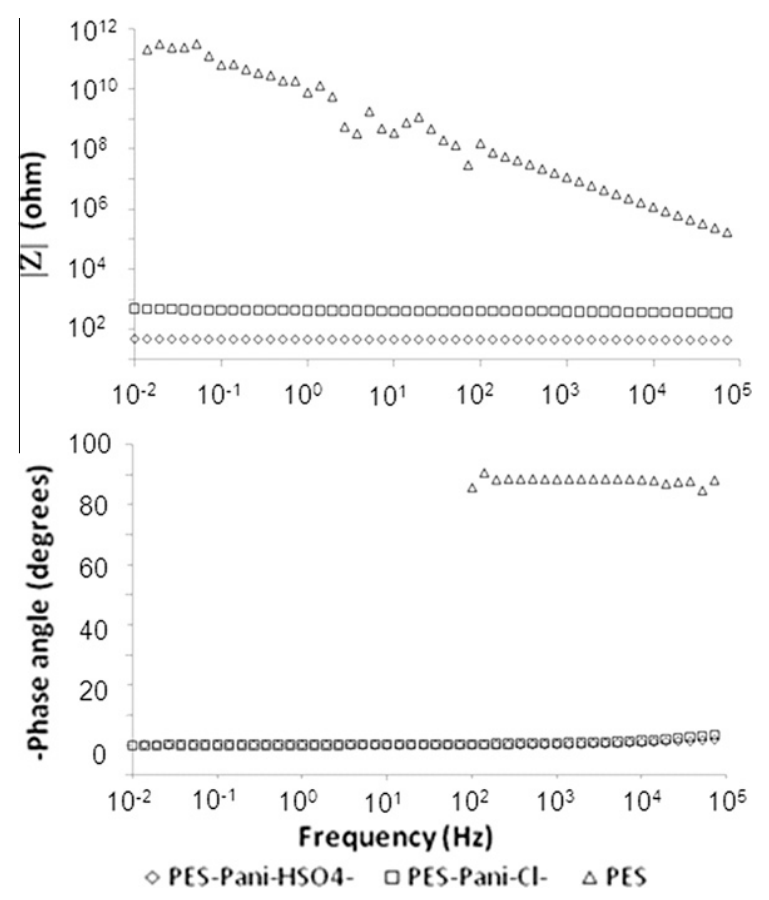

Fig. 6. Bode plots for PES, PES-Pani/HSO $\mathrm{HS}_{4}^{-}$and $\mathrm{PES}-\mathrm{Pani} / \mathrm{Cl}^{-}$. Sample located between two copper electrodes. Frequency range from $10^{5}$ to $10^{-2} \mathrm{~Hz}$. 
second configuration of the copper electrodes (see Section 2) showed also lower values for the sample coated with Pani/HSO $-\mathrm{HSO}_{4}^{-}$. The values obtained were 1500 and 19,000 $\Omega$ / $\square$ for PES-Pani/HSO ${ }_{4}^{-}$and PES-Pani/ $/ \mathrm{Cl}^{-}$respectively. Static charging of the surface of fibers is excluded with surface resistivities below $5 \cdot 10^{9} \Omega / \square[43]$, so the surface resistivity obtained with both fabrics is adequate for this purpose.

In Fig. 6b, it is shown the data for the phase angle at different frequencies for the same samples of the first diagram. Polyester has a phase angle of nearly $90^{\circ}$, the data at low frequencies $\left(10^{-2}-10^{2} \mathrm{~Hz}\right)$ is not shown since noise due to the large values of impedance modulus was observed. This value of phase angle is typical of insulating materials that act as a capacitor. Both conducting fabrics (PES-Pani $/ \mathrm{HSO}_{4}^{-}$and PES-Pani $/ \mathrm{Cl}^{-}$) showed $0^{\circ}$ of phase angle in the entire frequency range. This indicates that the samples acted as a resistor (conducting material) with different resistances that were indicated previously. So polyester changed its behavior from an insulating material to a conductor one after polyaniline deposition.

\subsection{Cyclic voltammetry measurements}

Cyclic voltammetry measurements were performed for the sample of PES-Pani/ $/ \mathrm{HSO}_{4}^{-}$in different $\mathrm{pH}$ solutions to test its electroactivity. The measurements were also made at different scan rates $\left(1,5\right.$ and $\left.50 \mathrm{mV} \mathrm{s}^{-1}\right)$ as we have corroborated the influence of the scan rate in the electrochemical characterization of conducting fabrics [28,44]. To compare the voltammograms in the different experiments, the fifth scan is shown for all the experiments.

Fig. 7 compares the voltammograms obtained for PES$\mathrm{Pani} / \mathrm{HSO}_{4}^{-}$in $0.5 \mathrm{M} \mathrm{H}_{2} \mathrm{SO}_{4}$ at the different scan rates employed (1, 5 and $50 \mathrm{mV} \mathrm{s}^{-1}$ ). With the highest scan rate, no redox processes could be observed in the voltammogram and a resistive response was obtained. When the scan rate decreased to $5 \mathrm{mV} \mathrm{s}^{-1}$, the form of the voltammogram broadened, although the redox peaks were not clearly defined. A higher decrease of the scan rate to $1 \mathrm{mV} \mathrm{s}^{-1}$ caused the apparition of two clear redox peaks; a reduction peak at $+0.17 \mathrm{~V}$ and an oxidation peak at $+0.57 \mathrm{~V}$. These peaks can be better observed in the voltammogram presented in Fig. 8. The form of the voltammogram is similar to that obtained in our previous work, where polyaniline was electrochemically deposited on polypyrrole coated fabrics [44]. The influence of the scan rate in the characterization of these materials by cyclic voltammetry is clear. Higher scan rates (like $50 \mathrm{mV} \mathrm{s}^{-1}$ ) do not allow the observation of redox processes. Polyester is an insulating material so the charge transfer is produced along polyaniline chains. If the scan rate is too fast, there is not sufficient time to allow the complete oxidationreduction of polyaniline and a resistive response is obtained. When the scan rate is decreased, there is more time to allow the transformation of the polymer and consequently the redox processes can be better observed. Cyclic voltammetry studies of conducting polymers have been made on metallic substrates mainly, where the charge transfer is produced between the metal-polymer interface instantaneously. Studies on metallic substrates employing different scan rates have demonstrated that the form of the

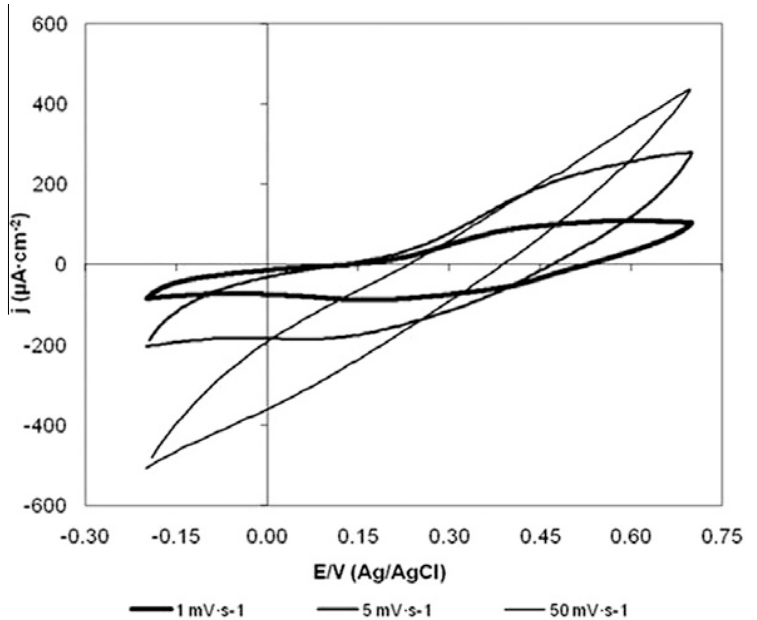

Fig. 7. Cyclic voltammograms of $\mathrm{PES}-\mathrm{Pani} / \mathrm{HSO}_{4}^{-}$, fifth scan for all measurements: $0.5 \mathrm{M} \mathrm{H}_{2} \mathrm{SO}_{4}(\mathrm{pH} \sim 0)$; 50,5 and $1 \mathrm{mV} \mathrm{s}^{-1}$.

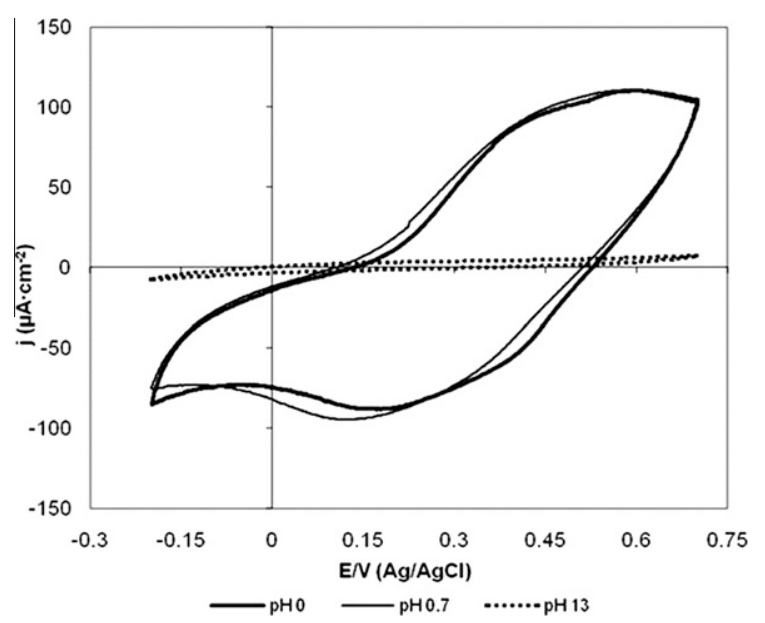

Fig. 8. Cyclic voltammograms of $\mathrm{PES}-\mathrm{Pani} / \mathrm{HSO}_{4}^{-}$, fifth scan for all measurements: $1 \mathrm{mV} \mathrm{s}^{-1}$; $\mathrm{pH} \sim 0, \mathrm{pH} \sim 0.7, \mathrm{pH} \sim 13$.

voltammogram is not changed by the scan rate, only the peak currents of the redox processes are affected [45]. If insulating substrates are employed, the charge transfer is not produced instantaneously, so the scan rate in this case is an important parameter to take into account.

In Fig. 8 the voltammograms employing the lowest san rate $\left(1 \mathrm{mV} \mathrm{s}^{-1}\right)$ in the different $\mathrm{pH}$ solutions $(0,0.7,13)$ are presented. The lowest scan rate has been employed since it has been demonstrated to produce the best electrochemical response. It can be seen that the same redox processes were observed in $0.1 \mathrm{M}$ and $0.5 \mathrm{M} \mathrm{H}_{2} \mathrm{SO}_{4}$, and only small variations of the voltammogram could be appreciated (for example the displacement of the reduction peak to $+0.12 \mathrm{~V}$ in $0.1 \mathrm{M} \mathrm{H}_{2} \mathrm{SO}_{4}$ ). On the other hand, the characterization of the fabric in the $\mathrm{pH} 13$ solution showed a great loss of electroactivity, attributed to the deprotonation of polyaniline that takes place at $\mathrm{pH}>4$ [46]. As the $\mathrm{pH}$ solution increases, the electroactivity of the conducting fabric decreases. 


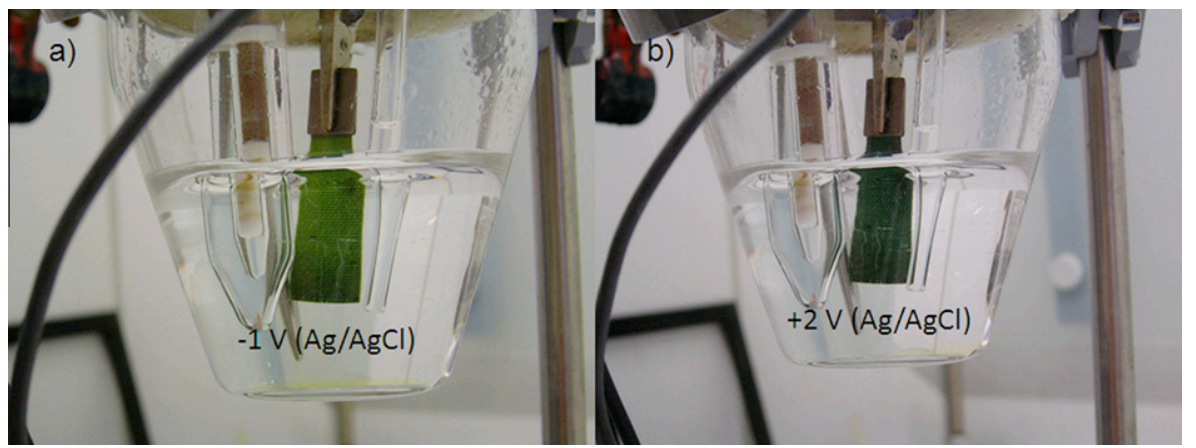

Fig. 9. Images of a sample of PES-Pani/ $\mathrm{HSO}_{4}^{-}$conducting fabric: (a) in the reduced form at $-1 \mathrm{~V}$, (b) in the oxidized form at $+2 \mathrm{~V}$.

Moreover, PES-Pani/HSO ${ }_{4}^{-}$fabrics have shown electrochromic properties, changing its color with the applied potential. Fig. 9a, shows the conducting fabric submitted to a reduction process at $-1 \mathrm{~V}$. As it can be seen the sample acquires a green yellowish color. On the other hand when the conducting fabric is subjected to an oxidation potential $(+2 \mathrm{~V})$ the sample shows a dark green color (Fig. 9b). Polyaniline shows different colors with the potential applied due to its different possible oxidation states [46].

\subsection{Scanning electrochemical microscopy}

SECM measurements were carried out for the samples of PES-Pani/ $\mathrm{HSO}_{4}^{-}$and PES-Pani/Cl${ }^{-}$. Approach $\left(I_{\mathrm{T}}-L\right)$ curves were recorded in the feedback mode in a $0.01 \mathrm{M}$ solution of $\mathrm{Ru}\left(\mathrm{NH}_{3}\right)_{6}^{3+}$ and $0.1 \mathrm{M} \mathrm{Na}_{2} \mathrm{SO}_{4}$ or $\mathrm{NaCl}$, for PESPani $/ \mathrm{HSO}_{4}^{-}$and PES-Pani $/ \mathrm{Cl}^{-}$, respectively. The electroactivity of the samples was measured in different $\mathrm{pH}$ media (2.4 and 5.4) since protonation is a key factor in the conductivity of polyaniline. The $\mathrm{pH}$ of the solutions was adjusted with $\mathrm{H}_{2} \mathrm{SO}_{4} / \mathrm{NaOH}$ and $\mathrm{HCl} / \mathrm{NaOH}$ for the samples of PES-Pani/HSO $\mathrm{HS}_{4}^{-}$and PES-Pani $/ \mathrm{Cl}^{-}$, respectively. A $100 \mu \mathrm{m}$ Pt ultramicroelectrode (UME) held at a potential of $-0.3 \mathrm{~V}$ (vs. $\mathrm{Ag} / \mathrm{AgCl} 3 \mathrm{M} \mathrm{KCl}$ ) was employed as the working electrode. According to the voltammograms obtained with the UME tip in these solutions (not shown), this potential was selected to reduce the oxidized form of the mediator, $\mathrm{Ru}\left(\mathrm{NH}_{3}\right)_{6}^{3+}$, at a diffusion-controlled rate.

Approach curves give an indication of the electroactivity of the electrode surface. If the surface is non conductive, when the electrode approaches the surface there is a decrease of the current measured (negative feedback) [20]. On the other hand, if the electrode is conductive, when the electrode approaches the surface of the substrate the current increases (positive feedback) [20]. Polyester samples were also measured to obtain the response of the substrate material without the polyaniline coating.

In approach curves, the normalized current registered at the UME $\left(I_{\mathrm{T}}(L)\right)$ is represented vs. the normalized distance $(L)$. The normalized current is defined as follows: $I_{\mathrm{T}}(L)=i / i_{\infty}$. $i$ is the current measured at each distance. $i_{\infty}$ is the diffusion current defined as: $i_{\infty}=4 \cdot n \cdot F \cdot D \cdot a \cdot C$, in which: $n$ is the number of electrons involved in the reaction; $F$ is the Faraday constant; $D$ is the diffusion coefficient; $a$ is the radius of the ultra-microelectrode (UME) and $C$ is the concentration of the reactant. The normalized currents depend on $\mathrm{RG}\left(\mathrm{RG}=R_{\mathrm{g}} / a\right.$, where $R_{\mathrm{g}}$ is the radius of the insulating glass surrounding the Pt tip of radius " $a$ ") and the normalized distance $L$; where $L=d / a$ ( $d$ is the UME-substrate separation). The RG of the UME tip employed in this work was $R G \geqslant 20$. According to Rajendran el al. [47], Pade's approximation gives a close and simple equation with less relative error for all distances and valid for $R G>10$. The approximate expression of the steadystate normalized current assuming positive feedback for finite conductive substrate together with finite insulating glass thickness is:

$I_{\mathrm{T}}^{C}=\left[\frac{1+1.5647 / L+1.316855 / L^{2}+0.4919707 / L^{3}}{1+1.1234 / L+0.626395 / L^{2}}\right]$

The election of the expression for the normalized tip current assuming negative feedback was based on the equation for a $R G=20$ and $L$ range $0.4-20$ [48]:

$I_{\mathrm{T}}^{\mathrm{INS}}=\left[\frac{1}{0.3554+2.0259 / L+0.62832 \times \exp (-2.55622 / L)}\right]$

Approach curves predicted for pure positive and negative feedback calculated from Eqs. 1 and 2 have been also included in the different figures to compare the empirical data with the theoretical models.

Fig. 10a, shows a selection of approach curves recorded at different points randomly chosen throughout the PESPani/ $/ \mathrm{HSO}_{4}^{-}$fabric. Positive feedback was obtained for all the curves and all of them almost followed the theoretical model for positive feedback (continuous line). This fact indicates that the surface of the sample presents homogeneous conducting areas, with fast heterogeneous kinetics at $-0.3 \mathrm{~V}$. In the same figure the approach curve for polyester has been represented (dotted line). It can be clearly seen the different behavior since polyester showed negative feedback, indicating its insulating nature. In Fig. 10b, approach curves for the sample of PES-Pani/Cl ${ }^{-}$are shown. The same conducting behavior than in the PES-Pani $/ \mathrm{Cl}^{-}$ sample was observed.

In Fig. 11a, approach curves for the PES-Pani/ $/ \mathrm{HSO}_{4}^{-}$ sample in the pH 5.4 solution are shown. It can be clearly observed the change in the behavior of the material. In the $\mathrm{pH} 5.4$ solution, negative feedback has been obtained 

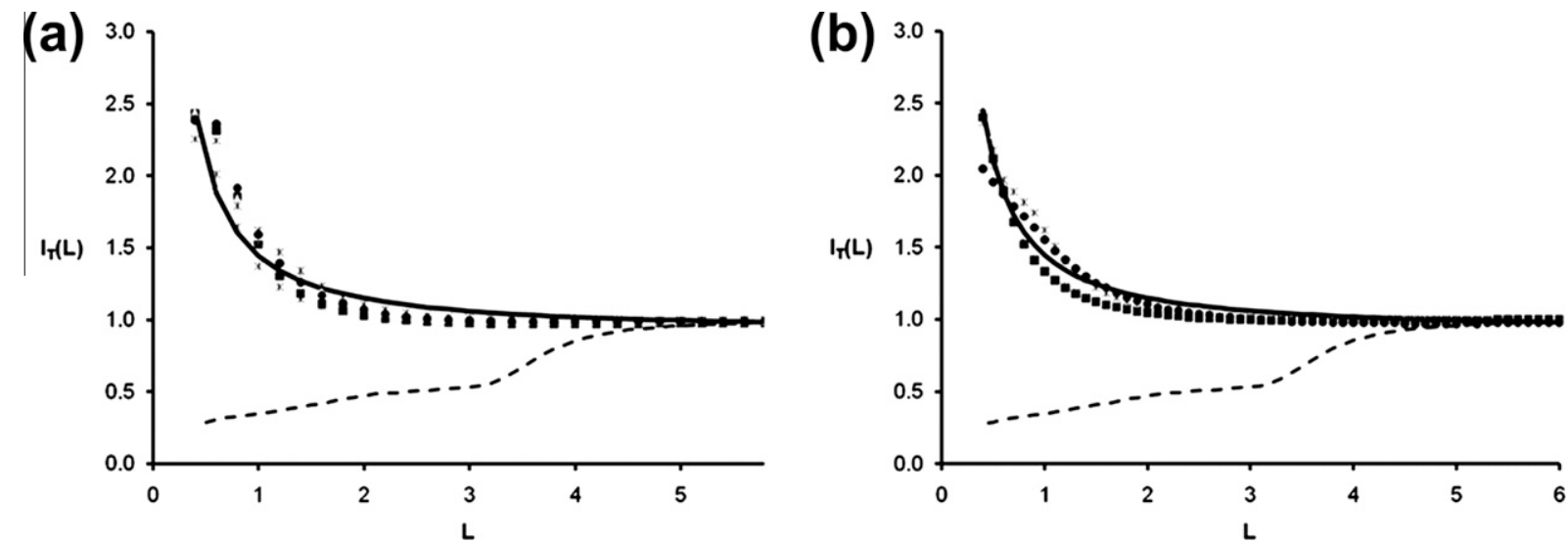

Fig. 10. Approach curves in $\mathrm{pH} 2.4$ solutions for: (a) PES-Pani/HSO $\mathrm{H}_{4}^{-}$and (b) PES-Pani/Cl- ${ }^{-}$. Approach curve for PES (- - -) and theoretical model for positive feedback (-) have also been included. Approach curves obtained with a $100 \mu \mathrm{m}$ diameter Pt tip in $0.01 \mathrm{M} \mathrm{Ru}^{\mathrm{N}}\left(\mathrm{NH}_{3}\right)_{6}^{3+}$ and $0.1 \mathrm{M} \mathrm{Na} \mathrm{SO}_{4}$ or $0.1 \mathrm{M} \mathrm{NaCl}$ solution for PES-Pani $/ \mathrm{HSO}_{4}^{-}$and $\mathrm{PES}-\mathrm{Pani} / \mathrm{Cl}^{-}$, respectively. $\mathrm{pH}$ adjusted to 2.4 . The tip potential was $-300 \mathrm{mV}(\mathrm{vs}$. $\mathrm{Ag} / \mathrm{AgCl})$ and the approach rate was $10 \mu \mathrm{m} \mathrm{s}^{-1}$.

for all the measurements. It can be seen that the curves follow in part the theoretical curve for negative feedback (continuous line). Approach curve for polyester has been also represented (dotted line) for comparison. At $\mathrm{pH}>4$ the deprotonation of polyaniline takes place with the consequent loss of conductivity (10 orders of magnitude) [46]. So at $\mathrm{pH} 5.4$ polyaniline is in its deprotonated and that causes the negative feedback observed for all the approach curves. For the sample of PES-Pani/ $/ \mathrm{Cl}^{-}$the same insulating behavior was observed (Fig. 11b).

One main application of SECM technique is scanning surfaces to obtain 2D and 3D images of the electrochemical activity [19]. According to approach curves obtained, a homogeneous and uniform coating of Pani on the PES fabric was obtained. Therefore, the topographical features of the textile substrate have more influence in the electrochemical response obtained than local differences of electroactivity of coating. This is clearly observed in the 2D and 3D SECM images of the PES-Pani/ $\mathrm{HSO}_{4}^{-}$substrate (Fig. 12). In the 2D image (Fig. 12a), it can be seen that

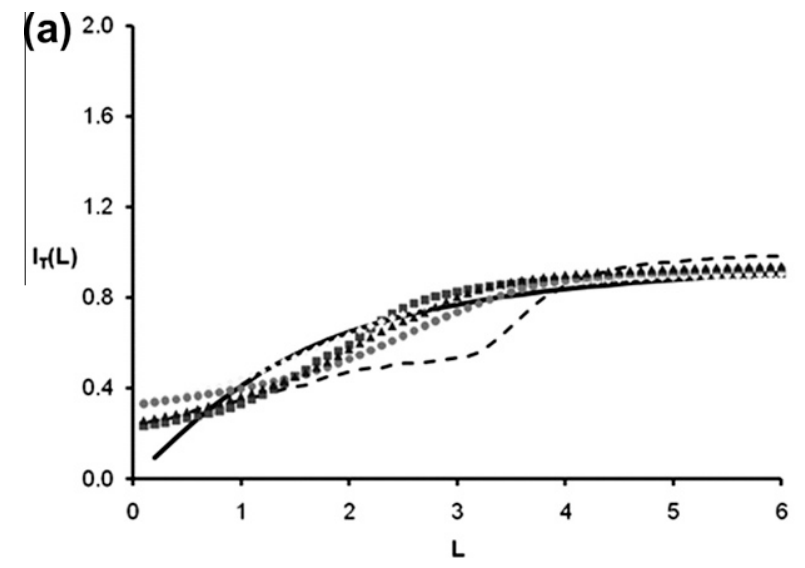

there is an increase of the current measured in some zones (darker zones). The more raised parts of the fabric produce an increase of the current. The lower parts of the fabric give smaller currents because the distance between the UME tip and the substrate is greater and the positive feedback influence is lower. The 3D image (Fig. 12b) exemplifies better the influence of the fabric topography on the electrochemical response obtained. The holes represent an increase of the current due to a major proximity of the substrate surface to the UME and, therefore, a major positive feedback influence.

\subsection{Washing and rubbing fastness tests}

Degradation of the coating after washing and rubbing fastness tests was evaluated by means of color degradation and color discharge according to the gray scale (ISO 105A02 and ISO 105-A03). Rubbing fastness test showed significant degradation of the coating with the loss of part of the conducting polymer. In the sample it could be

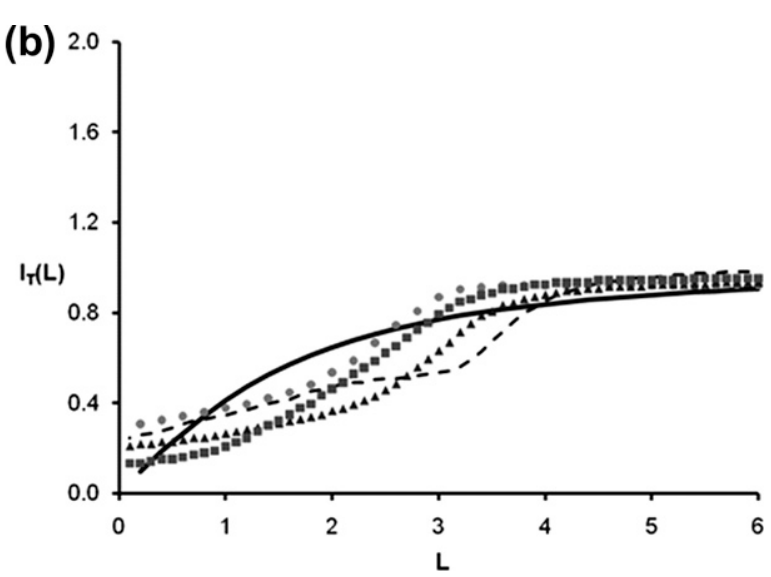

Fig. 11. Approach curves in pH 5.4 solutions for: (a) PES-Pani/HSO ${ }_{4}^{-}$and (b) PES-Pani/Cl- . Approach curve for PES (- - -) and theoretical model for negative feedback (-) have also been included. Approach curves obtained with a $100 \mu \mathrm{m}$ diameter Pt tip in $\left.0.01 \mathrm{M} \mathrm{Ru} \mathrm{NH}_{3}\right)_{6}^{3+}$ and $0.1 \mathrm{M} \mathrm{Na} \mathrm{SO}_{4}$ or $0.1 \mathrm{M} \mathrm{NaCl}$ solution for $\mathrm{PES}-\mathrm{Pani} / \mathrm{HSO}_{4}^{-}$and $\mathrm{PES}-\mathrm{Pani} / \mathrm{Cl}^{-}$, respectively. $\mathrm{pH}$ adjusted to 5.4 . The tip potential was $-300 \mathrm{mV}$ ( $\mathrm{vs}$. $\mathrm{Ag} / \mathrm{AgCl}$ ) and the approach rate was $10 \mu \mathrm{m} \mathrm{s}^{-1}$. 

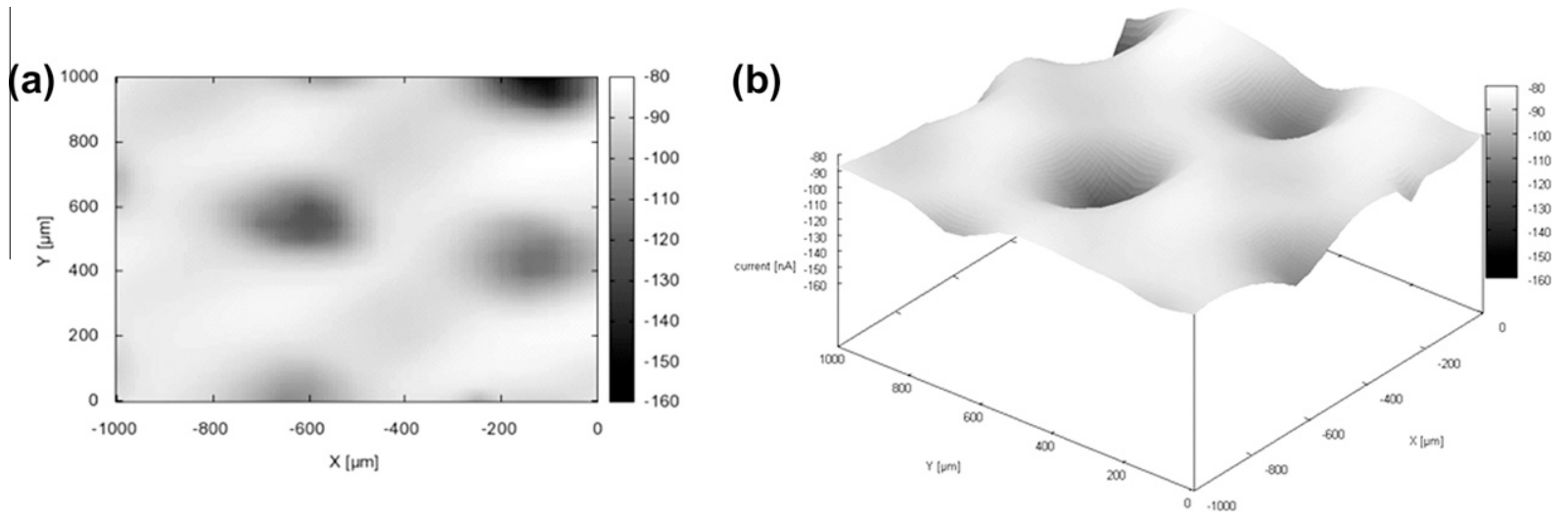

Fig. 12. $2 \mathrm{D}$ (a) and 3D (b) constant height SECM images of a PES-Pani/HSO Pt tip, in $0.01 \mathrm{M} \mathrm{Ru}\left(\mathrm{NH}_{3}\right)_{6}^{3+}(\mathrm{pH} 2.4)$ at a constant height of $60 \mu \mathrm{m}$. The scan rate was $100 \mu \mathrm{m} \mathrm{s}^{-1}$ in comb mode; lengths of $x$ and $y$ lines were $1000 \times 1000 \mu \mathrm{m}$ with increments of $50 \mu \mathrm{m}$.

distinguished the band that had been submitted to friction. Values of 1-2 for the color degradation and color discharge were obtained, indicating a significant degradation of the polyaniline layer. An increase in the resistance of the conducting fabric measured between the copper electrodes was also obtained (from 49 to $437 \Omega$ ). A way to improve the durability of the coating is plasma treatment. It has been proposed as an alternative to increase the adhesion between the fibers and the conducting polymer $[49,50]$. Plasma treatment creates reactive groups and radicals on the surface of the fabric. These groups allow the formation of dipolar interactions, Van der Waals forces or hydrogen bonds between the fabric and the coating, increasing the adhesion of the coating to the surface of the fabric [50]. Therefore, plasma treatment is a possibility that could be explored to improve the durability of the coatings.

The washing assay of the fabric coated with Pani/ $/ \mathrm{HSO}_{4}^{-}$ showed no degradation of the coating and values of 4-5 for color degradation and color discharge were obtained. In the case of the washing test, a color change of the conducting fabric from green (emeraldine salt) to blue (emeraldine base) was observed. The soap employed produces a basic $\mathrm{pH}$ of 9 and that causes the deprotonation of polyaniline and consequently a color change in the conducting fabric. The value of resistance measured by EIS changed from $49 \Omega$ to $>10^{10} \Omega$, indicating that the material behaved as an insulating material; the phase angle also changed from $0^{\circ}$ (conducting material) to $90^{\circ}$ (insulating material). Polyaniline protonation/deprotonation is a reversible process and the conducting form (emeraldine salt) can be obtained again after protonation in acid media (protonic acid doping) [51]. After protonating (with $0.2 \mathrm{M} \mathrm{H}_{2} \mathrm{SO}_{4}$ solution) the sample submitted to the washing test, the value of resistance lowered till the initial values measured for the as-synthesized fabric $(\sim 50 \Omega)$.

\section{Conclusions}

Fabrics of polyester have been coated with polyaniline chemically synthesized. Two doping acids have been employed $\left(\mathrm{H}_{2} \mathrm{SO}_{4}\right.$ and $\left.\mathrm{HCl}\right)$ and the best results have been achieved with $\mathrm{H}_{2} \mathrm{SO}_{4}$ media. X-ray photoelectron spectroscopy measurements showed higher doping level $\left(\mathrm{N}^{+} / \mathrm{N}\right)$ for PES-Pani $/ \mathrm{HSO}_{4}^{-}$samples (0.66) than for PES-Pani/ $/ \mathrm{Cl}^{-}$ones (0.28). This indicates a higher oxidation level of polyaniline chains in Pani $/ \mathrm{HSO}_{4}^{-}$coatings and consequently a more conductive polymer. Electrochemical impedance spectroscopy (EIS) measurements showed the change of the electrical properties of polyester when polyaniline was deposited on its surface. The phase angle changed from $90^{\circ}$ for polyester (indicating a capacitative behavior, typical of insulating materials) to $0^{\circ}$ for samples coated with polyaniline (indicating its conducting nature). Electrical measurements confirmed the results obtained by XPS since Pani/ $\mathrm{HSO}_{4}^{-}$coatings were more conductive than Pani $/ \mathrm{Cl}^{-}$ones. The values of conductivity obtained make these fabrics suitable materials for antistatic applications. Rubbing fastness tests showed an increase of the resistance of the PESPani/ $/ \mathrm{HSO}_{4}^{-}$fabric ( $\sim 9$ times). Washing tests showed a great increase of the resistance of the PES-Pani/ $/ \mathrm{HSO}_{4}^{-}$fabric due to the deprotonation of polyaniline. However, the conducting fabric regained the initial conductivity after protonating the sample with an acid media solution.

Cyclic voltammetry (CV) measurements showed that the best scan rate to characterize polyaniline coated conducting fabrics is $1 \mathrm{mV} \mathrm{s}^{-1}$. Higher scan rates (like $50 \mathrm{mV} \mathrm{s}^{-1}$ ) do not allow the observation of polyaniline redox processes. An increase of the measuring $\mathrm{pH}$ solution produced a decrease of the current density in the voltammograms due to the deprotonation of polyaniline at $\mathrm{pH}>4$. Scanning electrochemical microscopy (SECM) measurements showed that both conducting fabrics (PES-Pani/ $\mathrm{HSO}_{4}^{-}$and PES-Pani $/ \mathrm{Cl}^{-}$) behave like conducting materials. Both samples showed positive feedback and adjusted to the theoretical positive feedback model. When conducting fabrics were measured in pH 5.4, the electroactivity of both samples decreased dramatically due to the deprotonation of polyaniline. In $\mathrm{pH} 5.4$, negative feedback was obtained for both samples, indicating the loss of its electroactivity at this $\mathrm{pH}$. Conducting fabrics showed also electrochromic properties, changing its color from a green yellowish at $-1 \mathrm{~V}$ to a dark green at $+2 \mathrm{~V}$. 


\section{Acknowledgements}

Authors thank to the Spanish Ministerio de Ciencia e Innovación and European Union Funds (FEDER) (contract CTM2010-18842-C02-02) and Universitat Politècnica de València (Primeros Proyectos de Investigación (PAID-0610)) for the financial support. J. Molina is grateful to the Conselleria d'Educació (Generalitat Valenciana) for the FPI fellowship.

\section{References}

[1] Gregory RV, Kimbrell WC, Kuhn HH. Conductive textiles. Synth Met 1989;28(1-2):823-35.

[2] Hong KH, Oh KW, Kang TJ. Polyaniline-nylon 6 composite fabric for ammonia gas sensor. J Appl Polym Sci 2004;92(1):37-42.

[3] Dhawan SK, Singh N, Venkatachalam S. Shielding behaviour of conducting polymer-coated fabrics in $X$-band, $W$-band and radio frequency range. Synth Met 2002;129(3):261-7.

[4] Dhawan SK, Singh N, Venkatachalam S. Shielding effectiveness of conducting polyaniline coated fabrics at $101 \mathrm{GHz}$. Synth Met 2002;125(3):389-93.

[5] Aksit AC, Onar N, Ebeoglugil MF, Birlik I, Celik E, Ozdemir I. Electromagnetic and electrical properties of coated cotton fabric with barium ferrite doped polyaniline film. J Appl Polym Sci 2009;113(1):358-66.

[6] Kim B, Koncar V, Dufour C. Polyaniline-coated PET conductive yarns: study of electrical, mechanical, and electro-mechanical properties. J Appl Polym Sci 2006;101(3):1252-6.

[7] Tsekouras G, Ralph SF, Price WE, Wallace GG. Gold recovery using inherently conducting polymer coated textiles. Fibers Polym 2004;5(1):1-5

[8] Hirase R, Hasegawa M, Shirai M. Conductive fibers based on poly(ethylene terephthalate)-polyaniline composites manufactured by electrochemical polymerization. J Appl Polym Sci 2003;87(7):1073-8.

[9] Molina J, del Río AI, Bonastre J, Cases F. Electrochemical polymerisation of aniline on conducting textiles of polyester covered with polypyrrole/AQSA. Eur Polym J 2009:45(4):1302-15.

[10] Hirase R, Shikata T, Shirai M. Selective formation of polyaniline on wool by chemical polymerization, using potassium iodate. Synth Met 2004;146(1):73-7.

[11] Fryczkowski R, Rom M, Fryczkowska B. Polyester fibres finished with polyaniline. Fibres Text East Eur 2005;13(5):141-3.

[12] Kutanis S, Karakişla M, Akbulut U, Sacak M. The conductive polyaniline/poly(ethylene terephthalate) composite fabrics. Composites Part A 2007;38(2):609-14.

[13] Neelakandan R, Madhusoothanan M. Electrical resistivity studies on polyaniline coated polyester fabrics. J Eng Fibers Fabr 2010;5(3):16-24.

[14] Nouri M, Kish MH, Entezami AA, Edrisi M. Conductivity of textile fibers treated with aniline. Iran Polym J 2000;9(1):49-58

[15] Simal AL, de Souza AMC. Composites based on poly(ethylene terephthalate) fibers with polyaniline. I. Effect of the aniline monomer in the morphology of the PET substrate. J Appl Polym Sci 2000;77(10):2126-38.

[16] Simal AL, de Souza AMC. Composites based on poly(ethylene terephthalate) fibers with polyaniline. II. The effect of the growth of the polyaniline molecules during the polymerization in the morphology of the PET substrate. J Appl Polym Sci 2000;77(11):2346-62.

[17] Huang H, Liu W. Polyaniline/poly(ethylene terephthalate) conducting composite fabric with improved fastness to washing. J Appl Polym Sci 2006;102(6):5775-80.

[18] Wu J, Zhou D, Looney MG, Waters PJ, Wallace GG, Too CO. A molecular template approach to integration of polyaniline into textiles. Synth Met 2009;159(12):1135-40.

[19] Sun P, Laforge FO, Mirkin MV. Scanning electrochemical microscopy in the 21st century. Phys Chem Chem Phys 2007;9(7):802-23.

[20] Mirkin MV, Horrocks BR. Electroanalytical measurements using the scanning electrochemical microscope. Anal Chim Acta 2000;406(2):119-46.
[21] Barker AL, Gonsalves M, Macpherson JV, Slevin CJ, Unwin PR. Scanning electrochemical microscopy: beyond the solid/liquid interface. Anal Chim Acta 1999;385(1-3):223-40.

[22] Bard AJ, Fan FRF, Kwak J, Lev O. Scanning electrochemica microscopy - Introduction and principles. Anal Chem 1989;61(2):132-8.

[23] Arca M, Mirkin MV, Bard AJ. Polymer films on electrodes. 26. Study of ion transport and electron transfer at polypyrrole films by scanning electrochemical microscopy. J Phys Chem 1995;99(14):5040-50

[24] Xiang CH, Xie OJ, Hu JM, Yao SZ. Studies on electrochemical copolymerization of aniline with $O$-phenylenediamine and degradation of the resultant copolymers via electrochemical quartz crystal microbalance and scanning electrochemical microscope. Synth Met 2006;156(5-6):444-53.

[25] Zhou JF, Wipf DO. Deposition of conducting polyaniline patterns with the scanning electrochemical microscope. J Electrochem Soc 1997; 144(4):1202-7.

[26] Marck C, Borgwarth K, Heinze J. Generation of polythiophene micropatterns by scanning electrochemical microscopy. Chem Mater 2001:13(3):747-52.

[27] Kranz C, Gaub HE, Schuhmann W. Polypyrrole towers grown with the scanning electrochemical microscopy. Adv Mater 1996;8(8):634-7.

[28] Molina J, Fernández J, del Río AI, Lapuente R, Bonastre J, Cases F. Stability of conducting polyester/polypyrrole fabrics in different $\mathrm{pH}$ solutions. Chemical and electrochemical characterization. Polym Degrad Stab 2010;95(12):2574-83.

[29] Complete textile glossary, available from <http:// www.celaneseacetate.com/textile_glossary_filament_acetate.pdf $>$, 2001 [accessed 15.05.11].

[30] Blinova NV, Stejskal J, Trchová M, Prokes J, Omastová M. Polyaniline and polypyrrole: a comparative study of the preparation. Eur Polym J 2007;43(6):2331-41.

[31] Kuhn HH, Child AD. Electrically conducting textiles. In: Skotheim TA, Elsenbaumer RL, Reynolds JR, editors. Handbook of Conducting Polymers. New York: Marcel Dekker, Inc.; 1998. p. 993-1013.

[32] Molina J, del Río AI, Bonastre J, Cases F. Chemical and electrochemical polymerisation of pyrrole on polyester textiles in presence of phosphotungstic acid. Eur Polym J 2008;44(7):2087-98.

[33] Kang ET, Neoh KG, Tan KL. Polyaniline: a polymer with many intrinsic redox states. Prog Polym Sci 1998;23(2):277-324.

[34] Chauhan NPS, Ameta R, Ameta R, Ameta SC. Thermal and conducting behavior of emeraldine base (EB) form of polyaniline (PANI). Indian J Chem Technol 2011;18(2):118-22.

[35] Andanson J-M, Kazarian SG. In situ ATR-FTIR spectroscopy of poly(ethylene) terephthalate) subjected to high temperature methanol. Macromol Symp 2008;265(1):195-204.

[36] Al-Jabareen A, Illescas S, Maspoch ML, Santana OO. Effects of composition and transesterification catalysts on the physicochemical and dynamic properties of PC/PET blends rich in PC. J Mater Sci 2010;45(24):6623-33.

[37] Varesano A, Dall'Acqua L, Tonin C. A study on the electrical conductivity decay of polypyrrole coated wool textiles. Polym Degrad Stab 2005;89(1):125-32.

[38] Kang ET, Neoh KG, Woo YL, Tan KL X-ray photoelectron spectroscopic studies of $\mathrm{H}_{2} \mathrm{SO}_{4}$ protonated polyaniline. Polymer 1992;33(13):2857-9.

[39] Ribo JM, Dicko A, Tura JM, Bloor D. Chemical structure of polypyrrole: X-ray photoelectron spectroscopy of polypyrrole with 5-yliden-3-pyrrolin-2-one end groups. Polymer 1991;32(4): 728-32.

[40] Han MG, Im SS. X-ray photoelectron spectroscopy study of electrically conducting polyaniline/polyimide blends. Polymer 2000;41(9):3253-62.

[41] Jousseaume V, Morsli M, Bonnet A. XPS study of aged polyaniline films. J Appl Polym Sci 2003;90(13):3730-6.

[42] Pud AA, Rogalsky SP, Shapoval GS, Korzhenko AA. The polyaniline (polyethylene terephthalate)/composite 1 . Peculiarities of the matrix aniline redox polymerization. Synth Met 1999;99(2): $175-9$.

[43] Textor T, Mahltig B. A sol-gel based surface treatment for preparation of water repellent antistatic textiles. Appl Surf Sci 2010;256(6):1668-74. 
[44] Molina J, del Río AI, Bonastre J, Cases F. Influence of the scan rate on the morphology of polyaniline grown on conducting fabrics. Centipede-like morphology. Synth Met 2010;160(1-2):99-107.

[45] Bhadani SN, Gupta MK, Sen Gupta SK. Cyclic voltammetry and conductivity investigations of polyaniline. J Appl Polym Sci 1993;49(3):397-403.

[46] MacDiarmid AG. Synthetic metals: a novel role for organic polymers. Synth Met 2002;125(1):11-22.

[47] Rajendran L, Ananthi SP. Analysis of positive feedback currents at the scanning electrochemical microscope. J Electroanal Chem 2004;561:113-8.
[48] Bard AJ, Mirkin MV. Scanning electrochemical microscopy. New York: Marcel Dekker, Inc.; 2001.

[49] Oh KW, Kim SH, Kim EA. Improved surface characteristics and the conductivity of polyaniline-nylon 6 fabrics by plasma treatment. J Appl Polym Sci 2001;81(3):684-94.

[50] Garg S, Hurren C, Kaynak A. Improvement of adhesion of conductive polypyrrole coating on wool and polyester fabrics using atmospheric plasma treatment. Synth Met 2007;157(1):41-7.

[51] Oh KW, Hong KH, Kim SH. Electrically conductive textiles by in situ polymerization of aniline. J Appl Polym Sci 1999;74(8): 2094-101. 